\title{
Can the Negative Appendicectomy Rate be Minimized?
}

\author{
Chandio A, Chandio K, Hussain A, Shaikh Z, Najeeb M, Naqvi S, Memon A, Munasinghe A \\ Department of General \& Laparoscopic Surgery Luton \& Dunstable University Hospital Lewsey \\ Road, Luton LU4 ODZ (United Kingdom) \\ *Corresponding Author: Mr Ashfaq Chandio, Department of General \& Laparoscopic Surgery Luton \\ \& Dunstable University Hospital Lewsey Road, Luton LU4 ODZ (United Kingdom)
}

\begin{abstract}
Background: Acute abdominal pain represents a vast inpatient burden of diverse diagnoses. Historically, the care of this group of patients has been overlooked and underfunded and there has been resultant variability in the quality of care provided.

Negative appendicectomy exposes patients to avoidable anesthesia and surgical complications, and it can be due to improper clinical assessment, unavailability of diagnostic modalities.

Aim: To identifying all patients presenting with suspected acute appendicitis and determine the negative appendicectomy rate.

Methods: This was a retrospective study of patients who presented to the emergency department or referred by a GP, between May 2018 to April 2019.A surgical team on call established the clinical diagnosis. Management, including discharge home, laboratory tests, Imaging, admission for observation, and operation was based on the surgeon's clinical assessment and decision.

Results: 273 patients underwent appendicectomy; out of them 147 (53.84\%) males and 126 (46.15\%) females. Positive appendicectomy (PA) was proven in 241 cases (88.27\%), while 32 cases (11.72\%) had negative appendicectomy.
\end{abstract}

Conclusion: More conscientiousness is required in making clinical diagnosis of acute appendicitis; our negative appendicectomy rate is comparable with that of literature

\section{INTRODUCTION}

Right iliac fossa pain is one of the most common presentations to the acute surgical take. The lifetime risk of having appendicitis is $7 \%$ $8 \%$ with an overall incidence of 11 cases per 10,000 populations per year. ${ }^{1,2,3}$ This condition is most commonly seen in patients aged between early teens and late $40 \mathrm{~s}$; there is a slight male to female predominance. Classic presentations of appendicitis may only occur in $50 \%$ of people, ${ }^{4,5,6}$, and establishing the diagnosis of acute appendicitis remains challenging. Diagnosis is based on history, clinical examination and supported by radiology and laboratory tests such as white blood cell (WBC) count and C-reactive protein $(\mathrm{CRP}) .{ }^{7,8}$ The risk of complications with appendicitis rises with the duration of symptoms, and these can be life-threatening if they are not managed promptly. In some patients, who present with a typical history and convincing examination signs, it is easy to determine what their management, but those with less specific signs can be more of a diagnostic challenge. It is these patients that require further time and investigations to determine the correct diagnosis and subsequent treatment. Appendicitis account for more than 40,000 hospital admissions in England each year. The rate of appendicectomy is around 10 per 10,000 cases per year in the US. ${ }^{9}$ Negative appendicectomy rates in the literature range from $2-41 \%$ and several authors consider higher negative appendicectomy rates acceptable in order to minimize the incidence of perforation. UK National audit in 2012 found the negative appendicectomy rate to be $20.6 \%$. ${ }^{10}$ There is huge intra- and inter-hospital variability in the management of these patients ${ }^{11}$ 
AIM

To identifying all patients presenting with suspected acute appendicitis and determine the negative appendicectomy rate.

\section{MeTHOdS}

This is a retrospective study of patients who presented to the emergency department or who were referred by General Practitioner (GP), between May 2018 and April 2019. Data were retrieved by detailed review of the hospital case notes, including blood tests, radiographic imaging and operative course. The following data fields were collected: Age, Gender, Presenting complaint, Comorbidities, Admission status, Date of admission, Date of operation, Date of discharge, Histology, overall care pathway and outcome.

Inclusion criteria: all patients referred to the on call surgical team with suspected appendicitis and who underwent appendicectomy.

Exclusion criteria Patients with concurrent Urological / Gynaecological problems or underwent diagnostic laparoscopy for investigative purposes were excluded from the study.

Laparoscopic Appendicectomy was undertaken via a standard 3-port method, achieving pneumoperitoneum using the Hasson / Veress technique. Open Appendicectomy was performed in conventional manner by Lanz incision.

\section{STATISTICAl AnAlysis}

Data were analyzed using the Statistical Package for Social Sciences (SPSS, version 24). Multivariable logistic regression models were created to explore the factors associated with negative appendicectomy, readmission, surgical site infection, intra-abdominal abscess and reintervention. Mean values were compared using the Student $t$ test. Univariate analysis of categorical variables was performed by the chi- square test. Chi-square was estimated for the significance between negative appendicectomy and presenting complaint and clinical examination findings. The t-test was used to test the significance between negative appendicectomy and blood test results. For all tests the $\mathrm{p}$ value was considered Statistically significant if it was $<0.05$.

\section{RESULTS}

273 patients underwent appendicectomy; out of them 147 (53.8\%) males and 126 (46.15\%) females. Positive appendicectomy was proven in 241 cases (88.3\%), while 32 cases (11.7\%) underwent a negative appendicectomy(Table 1). In the negative appendicectomy sample, 19 cases $(59.4 \%)$ were females and 13 cases $(40.6 \%)$ were males. There was no significant relationship between negative appendicectomy and gender (Table 2).Most admissions were in the younger age group between 5 and 45 years (Fig: 1). There was a significant association between negative appendicectomy in males aged 16 - 35 years $(\mathrm{p}<0.05$.) and females aged $11-$ 45 years $(\mathrm{p}<0.05$. $)$

Appendicectomy rates were highest in the month of August 2018 (12.1\%) and lowest in April 2019 (4.4 \%). The negative appendicectomy rate was greatest in November 2018 (21.9\%) and but lowest, at zero, during September 2018 and April 2019 (Fig: 2a, 2b). Histopathological examination showed 32 cases $(11.72 \%)$ without acute inflammation, 13 cases (4.76\%) with mild inflammation, faecolith in 12 cases $(4.39 \%)$, parasites in 2 cases $(0.73 \%)$, fibrous obliteration in 2 cases $(0.73 \%)$, and tumor in 1 case (0.36\%) (Fig: 3). Operative findings were reported as 'normal appendix' in 12 cases (4.39\%), gross inflammation in 18 cases (6.59\%), and mild inflammation in 17 $(6.22 \%)$ cases. Average length of stay in hospital was 3.44 days (range $1-23$ ) (Fig: 4).

\begin{tabular}{|c|c|c|c|c|c|}
\hline & \multicolumn{2}{|r|}{ Male } & \multicolumn{2}{|r|}{ Female } & Marginal Row Totals \\
\hline Inflammed Appendix & & (129.77) [0.08] & 108 & (111.23) [0.09] & 241 \\
\hline Histology Normal & & $(17.23) \quad[0.61]$ & 18 & $(14.77) \quad[0.71]$ & 32 \\
\hline Marginal Column Totals & & 147 & & 126 & 273 (Grand Total) \\
\hline
\end{tabular}

Chi-square $=1.49, p=0.22$.

Chi-square statistic with Yates correction $=1.0622$, $p$-value $=0.30$ 
Can the Negative Appendicectomy Rate be Minimized?

Table1.

\begin{tabular}{|l|c|c|c|c|c|c|c|c|c|c|c|}
\hline $\begin{array}{l}\text { Age in } \\
\text { Years }\end{array}$ & \multicolumn{3}{|c|}{ Gender } & \multicolumn{3}{|c|}{ Histological Findings } \\
\hline Age & Male & Female & Normal & Inflammed & Mild infl & Normal & Mild infl. & Cancer & Parasite & Faecolith & Obliteration \\
\hline $\mathbf{5}-\mathbf{1 0}$ & 15 & 9 & 0 & 0 & 2 & 0 & 2 & 0 & 0 & 0 & 0 \\
\hline $\mathbf{1 1}-\mathbf{1 5}$ & 20 & 14 & 2 & 1 & 2 & 2 & 3 & 0 & 0 & 0 & 0 \\
\hline $\mathbf{1 6}-\mathbf{2 0}$ & 17 & 10 & 2 & 4 & 4 & 5 & 5 & 0 & 1 & 4 & 0 \\
\hline $\mathbf{2 1}-\mathbf{2 5}$ & 13 & 15 & 1 & 2 & 3 & 4 & 1 & 0 & 0 & 2 & 1 \\
\hline $\mathbf{2 6}-\mathbf{3 0}$ & 14 & 13 & 3 & 1 & 3 & 6 & 1 & 0 & 0 & 2 & 0 \\
\hline $\mathbf{3 1}-\mathbf{3 5}$ & 17 & 10 & 2 & 3 & 3 & 8 & 0 & 0 & 1 & 2 & 1 \\
\hline $\mathbf{3 6}-\mathbf{4 0}$ & 8 & 12 & 1 & 1 & 0 & 2 & 0 & 0 & 0 & 1 & 0 \\
\hline $\mathbf{4 1}-\mathbf{4 5}$ & 14 & 8 & 0 & 2 & 0 & 1 & 1 & 0 & 0 & 0 & 0 \\
\hline $\mathbf{4 6}-\mathbf{5 0}$ & 9 & 5 & 0 & 2 & 0 & 2 & 0 & 0 & 0 & 1 & 0 \\
\hline $\mathbf{5 1}-\mathbf{5 5}$ & 4 & 11 & 1 & 0 & 0 & 1 & 0 & 0 & 0 & 0 & 0 \\
\hline $\mathbf{5 6}-\mathbf{6 0}$ & 6 & 6 & 0 & 2 & 0 & 1 & 0 & 1 & 0 & 0 & 0 \\
\hline $\mathbf{6 1}-\mathbf{6 5}$ & 2 & 4 & 0 & 0 & 0 & 0 & 0 & 0 & 0 & 0 & 0 \\
\hline $\mathbf{6 6}-\mathbf{7 0}$ & 3 & 3 & 0 & 0 & 0 & 0 & 0 & 0 & 0 & 0 & 0 \\
\hline $\mathbf{7 1}-\mathbf{7 5}$ & 2 & 1 & 0 & 0 & 0 & 0 & 0 & 0 & 0 & 0 & 0 \\
\hline $\mathbf{7 6}-\mathbf{8 0}$ & 2 & 1 & 0 & 0 & 0 & 0 & 0 & 0 & 0 & 0 & 0 \\
\hline $\mathbf{8 1}-\mathbf{8 5}$ & 1 & 2 & 0 & 0 & 0 & 0 & 0 & 0 & 0 & 0 & 0 \\
\hline $\mathbf{8 6}-\mathbf{9 0}$ & 0 & 2 & 0 & 0 & 0 & 0 & 0 & 0 & 0 & 0 & 0 \\
\hline Total & 147 & 126 & 12 & 18 & 17 & 32 & 13 & 1 & 2 & 12 & 2 \\
\hline
\end{tabular}

Table2.

\begin{tabular}{|l|c|c|c|c|c|c|c|}
\hline Month & \multicolumn{2}{|c|}{ Gender } & \multicolumn{2}{c|}{ Operative Findings } & \multicolumn{2}{c|}{ Histological Findings } \\
\hline & Male & Female & Normal & Inflammed & Mild inflammation & Normal & Mild infl \\
\hline May18 & 0 & 1 & 0 & 0 & 1 & 1 & 0 \\
\hline Jun-18 & 2 & 1 & 0 & 2 & 1 & 3 & 0 \\
\hline Jul-18 & 1 & 1 & 0 & 0 & 2 & 2 & 0 \\
\hline Aug18 & 0 & 3 & 1 & 1 & 0 & 3 & 0 \\
\hline Sep-18 & 0 & 0 & 0 & 0 & 0 & 0 \\
\hline Oct-18 & 1 & 1 & 0 & 2 & 0 & 2 & 0 \\
\hline Nov18 & 3 & 4 & 2 & 3 & 2 & 3 & 0 \\
\hline Dec18 & 0 & 3 & 2 & 0 & 1 & 6 & 0 \\
\hline Jan-19 & 3 & 3 & 2 & 2 & 2 & 2 & 0 \\
\hline Feb-19 & 1 & 1 & 1 & 0 & 1 & 3 & 0 \\
\hline Mar19 & 2 & 1 & 0 & 1 & 0 & 32 & 0 \\
\hline Apr-19 & 0 & 0 & 0 & 0 & 11 & 13 & 0 \\
\hline Total & 13 & 19 & 8 & 11 & & 0 \\
\hline
\end{tabular}

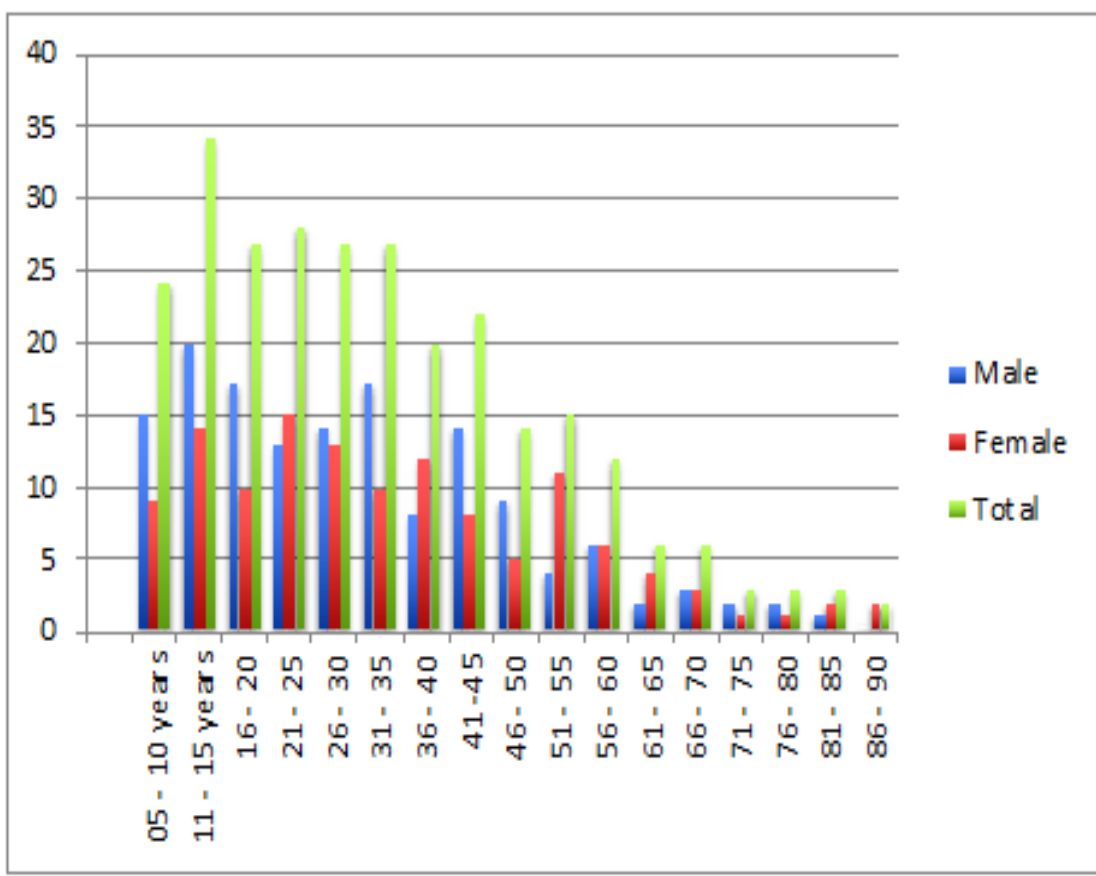

Fig1. 
Can the Negative Appendicectomy Rate be Minimized?

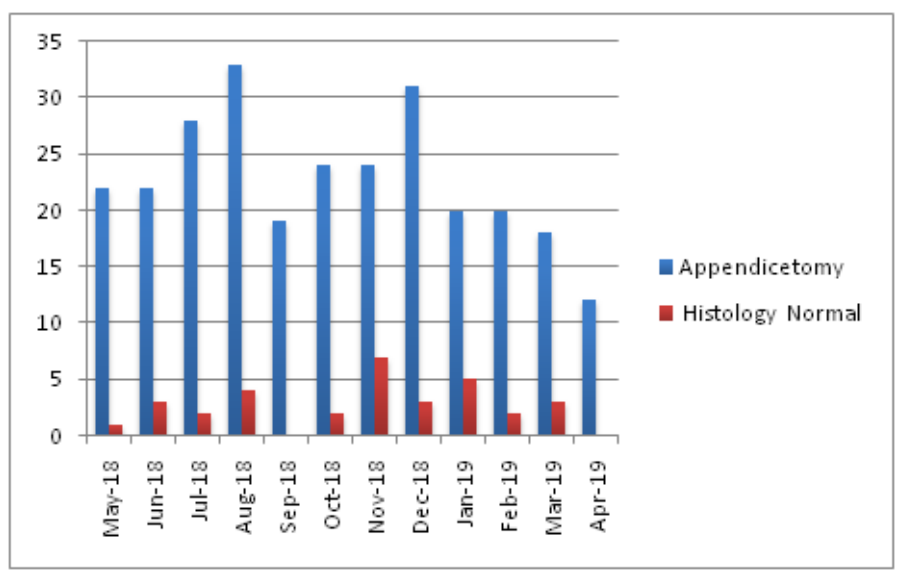

Fig2A.

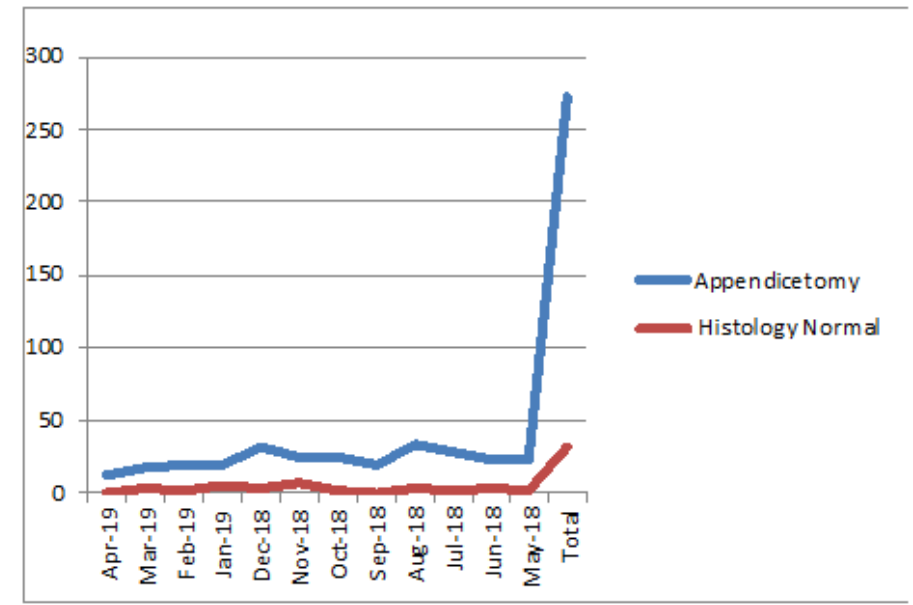

Fig2B.

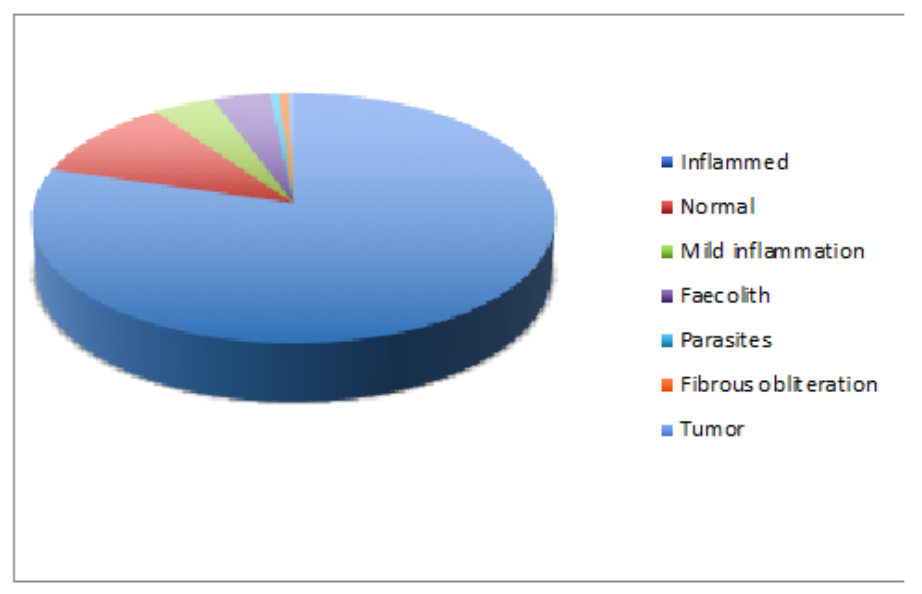

Fig3.

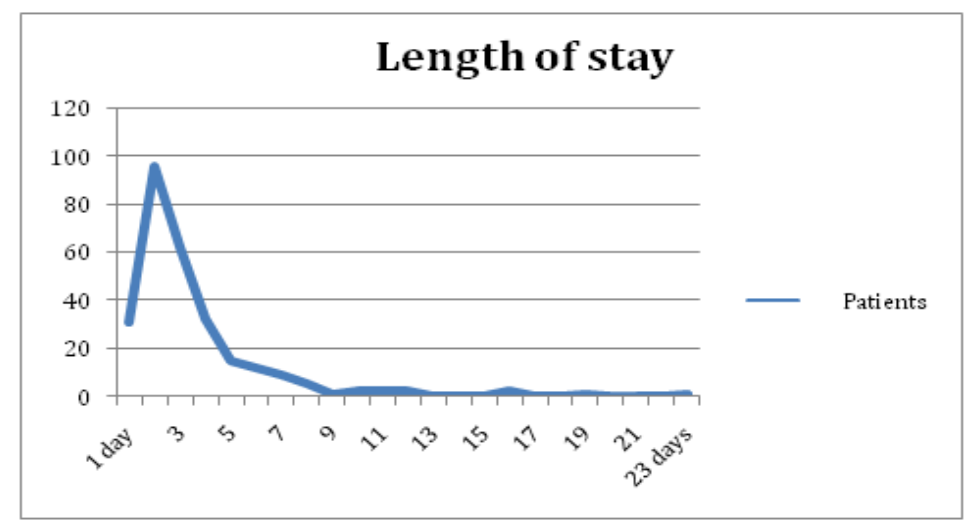

Fig4. 


\section{DISCUSSION}

Acute appendicitis is conventionally a clinical diagnosis; though, not all patients present with the 'typical' symptoms and signs of acute appendicitis. The clinical presentation can vary from mild symptoms to signs of generalized peritonitis and sepsis. The diagnosis of appendicitis can be challenging even in the most experienced of clinical hands, hence, the significance of individual clinical variables to establish the likelihood of acute appendicitis in a patient is low. ${ }^{12,13}$ Biochemical testing is performed routinely in most patients, but its significance in confirming acute appendicitis is debatable. Systematic review showed that elevated CRP levels render the highest diagnostic accuracy followed by increased numbers of leucocytes ${ }^{13}$. Complicated appendicitis (perforation or intra-abdominal abscess) is more likely the greater the duration of symptoms ${ }^{14}$ and in older patients $(>50$ years), ${ }^{15}$ if clinical findings suggest acute appendicitis, further investigations should not delay proceeding to surgical management. ${ }^{16}$ Appendicectomy is still considered to be the gold standard; initial non-operative management of appendicitis has been investigated in the adult population. Randomized controlled trials reported an effectiveness of 41-85 \% at 1-year follow-up ${ }^{17-21}$. Meta-analyses of these studies revealed that non-operative treatment of acute appendicitis is less effective but could avoid surgery in $60-85 \%$ of patients ${ }^{22-27}$ This approach may raise concerns of recurrent symptoms, missed malignancy, and the progression of uncomplicated into complicated appendicitis. Due to the possible avoidance of surgery with an initial non-operative treatment strategy, morbidity may be diminished. ${ }^{24,}{ }^{26,28} \mathrm{In}$ this study most appendicectomies were in the young age group between 5 and 45 years, and a significant relationship was reported between negative appendicectomy and males of 16 - 35 years and females of $11-45$ years. These findings are comparable to studies by Primatesta ${ }^{29}$ and Bhopal et aI. ${ }^{30}$ The lifetime chance of appendicectomy can be as high as $20 \%{ }^{31,32}$ The negative appendicectomy rate is a well-known in the treatment of patients with suspected appendicitis. ${ }^{33}$ In previous decades, a negative appendicectomy rate of between $15 \%$ and $25 \%$ has been accepted as reasonable. ${ }^{34}$

The contemporary negative appendectomy rate varies from $6 \%$ in the United States (routine use of preoperative imaging) and Switzerland (routine use of laparoscopy) to $21 \%$ in the United Kingdom (selective use of imaging and laparoscopy). ${ }^{35-37}$ The negative appendicectomy rate found in this study was $11.72 \%$ and this is within the traditional measures of acceptance and consistent with literature. There is inconsistency regarding the management of an unexpected "normal appendix" during diagnostic laparoscopy. ${ }^{38,}{ }^{39}$ if no other pathology is identified. The decision to remove the appendix should be considered but based on the individual clinical scenario. Macroscopically normal appendices may have abnormal histopathology. Several studies have shown a $19 \%$ - $40 \%$ rate of pathologically abnormal appendix in the setting of no macroscopic abnormalities. ${ }^{40}$ Therefore, the risk of leaving a potentially abnormal appendix must be weighed against the risk of appendicectomy in each individual scenario. Cases of postoperative symptoms requiring reoperation for appendicectomy have been described in patients whose normal appendix was left in place at the time of the original procedure. Patients are usually discharged from hospital one day after the operation for uncomplicated appendicitis. Our average length of stay was 3.44 days (range 1 - 23 days) and this is in consistent with the study of Bhopal et al. ${ }^{30}$ and Baigrje et al. ${ }^{41}$ who reported postoperative a length of stay of 4.1 days. The longer period of hospital stay in our study was due to complicated appendicitis, or perforated or gangrenous appendix.

The limitations of this study were that only patients who had an appendicectomy were studied, while patients who had suspected appendicitis and managed conservatively were not included. The use of the negative appendicectomy rate as a quality indicator is debatable - primarily that it does not specify resolution of clinical symptoms. It is likely that patients with negative appendicectomy had an improvement in their symptoms following appendicectomy. Many diseases resemble the presentation of acute appendicitis. Subsequently, more effort would be directed toward reducing negative appendicectomy rates and its complications.

\section{CONCLUSION}

More conscientiousness is required in making a clinical diagnosis of acute appendicitis; our negative appendicectomy rate is comparable with that of literature. 


\section{REFERENCE}

[1] Petroianu A. Diagnosis of acute appendicitis. Int J Surg 2012;10(3): 115-119.

[2] Shelton T, McKinlay R, Schwartz RW. Acute appendicitis: current diagnosis and treatment. Curr Surg 2003;60(5): 502-505.

[3] Addiss DG, Shaffer N, Fowler BS, Tauxe RV. The epidemiology of appendicitis and appendectomy in the United States. Am J Epidemiol 1990;132(5): 910-925.

[4] Jones, D. (1992) ABC of colorectal diseases. Appendicitis. BMJ. 305 (6844), 44-47.

[5] Lewis, S., Mahony, P. and Simpson, J. (2011) Appendicitis. BMJ. 343, d5976. [Abstract]

[6] Cox, J. and Sovak, G. (2015) Missed appendicitis diagnosis: A casereport. Journal of the Canadian Chiropractic Association.59 (3), 294-299. [Abstract]

[7] Yu CW, Juan LI, Wu MH, Shen CJ, Wu JY, Lee CC. Systematic review and meta analysis of the diagnostic accuracy of procalcitonin, Creactive protein and white blood cell countfor suspected acute appendicitis. British Journal of Surgery. 2013 Feb 1; 100(3): 322-329.

[8] Florence M, Flum DR, Jurkovich GJ, Lin P, Steele SR, Symons RG, Thirlby R. Negative appendectomy and imaging accuracy in the Washington state surgical care and outcomes assessment program. Annals of surgery. 2008 Oct 1; 248(4): 557-563.

[9] Flum DR, Koepsell TD. The clinical and economic correlates of misdiagnosed appendicitis: nationwide analysis. Arch Surg. 2002; 137:799-804. Full text Abstract

[10] National Surgical Research Collaborative. Multicentre observational study of performance variation in provision and outcome of emergency appendicectomy. Br. J. Surg. 2013; 100: $1240-52$.

[11] Multicentre observational study of performance variation in provision and outcome of emergency appendicectomy. $\mathrm{Br} \quad J$ Surg 2013;100(9): 1240-1252.

[12] Bundy DG, Byerley JS, Liles EA, Perrin EM, Katznelson J, Rice HE (2007) Does this child have appendicitis? JAMA 298:438-451

[13] Andersson RE (2004) Meta-analysis of the clinical and laboratory diagnosis of appendicitis. Br J Surg 91:28-37

[14] Temple CL, Shirley AH, Temple WJ. The natural history of appendicitis in adults. A prospective study.Ann Surg. 1995;221:278281. Full text Abstract

[15] Franz MG, Norman J, Fabri PJ. Increased morbidity of appendicitis with advancing age. Am Surg.1995; 61:40-44. Abstract

[16] Musunuru S, Chen H, Rikkers LF, et al.
Computed tomography in the diagnosis of acute appendicitis: definitive or detrimental? J Gastrointest Surg. 2007;11:1417-1421. Abstract

[17] Hansson J, Ko“rner U, Khorram-Manesh A, Solberg A, Lundholm K (2009) Randomized clinical trial of antibiotic therapyversus appendectomy as primary treatment of acute appendicitisin unselected patients. Br J Surg 96:473-481

[18] Eriksson S, Granstrom L (1995) Randomized clinical trial of appendectomy versus antibiotic therapy for acute appendicitis.Br J Surg 82:166-169

[19] Styrud J, Eriksson S, Nilsson I, Ahlberg G, Haapaniemi S, Neovius G, Rex L, Badume I, Granstrom L (2006) Appendectomy versus antibiotic treatment in acute appendicitis. A prospective multicentre randomized controlled trial. World JSurg 30:1033-1037

[20] Malik AA, Bari S (2009) Conservative management of acute appendicitis. J Gastrointest Surg 13:966-970

[21] Vons C, Barry C, Maitre S, Pautrat K, Leconte M, Costaglioli B, Karoui M, Alves A, Dousset B, Valleus P, Falissard B, Franco D (2011) Amoxicillin plus clavulanic acid versus appendicectomy for treatment of acute uncomplicated appendicitis. An openlabel, noninferiority, randomised controlled trial. Lancet 377:1573-1579

[22] Wilms IMHA, de Hoog DENM, de Visser DC, Janzing HMJ (2011) Appendectomy versus antibiotic treatment for acute appendicitis (review). Cochrane Database Syst Rev. doi:10. 1002/14651858.CD008359.pub2

[23] Svensson JF, Hall NJ, Eaton S, Pierro A, Wester T (2012) Areview of conservative treatment of acute appendicitis. Eur JPediatr Surg 22:185-194

[24] Mason RJ, Moazzez A, Sohn H, Katkhouda N (2012) Metaanalysisof randomized trials comparing antibiotic therapy with appendectomy for acute uncomplicated (no abscess or phlegmon)appendicitis. Surg Infect (Larchmt) 13:74-84

[25] Kirby A, Hobson RP, Burke D, Cleveland V, Ford G, West RM (2015) Appendicectomy for suspected uncomplicated appendicitisis associated with fewer complications than conservative antibiotic management: a meta-analysis of postinterventioncomplications. J Infect 70:105-110

[26] Varadhan KK, Neal KR, Lobo DN (2012) Safety and efficacy of antibiotics compared with appendicectomy for treatment of uncomplicated acute appendicitis: meta analysis of randomized controlled trials. BMJ. doi:10.1136/bmj.e2156

[27] Ansaloni L, Catena F, Coccolini F, Ercolani G, Gazzotti F, Pasqualini E, Pinna AD (2011) 
Surgery versus conservative antibiotic treatment in acute appendicitis: a systematic review and meta-analysis of randomized controlled trials. Dig Surg28:210-221

[28] Liu K, Fogg L (2011) Use of antibiotics alone for treatment of uncomplicated acute appendicitis: a systematic review andmetaanalysis. Surgery 150:673-683

[29] Primatesta P, Goldcare MJ. Appendiccctomy for acute appendicitis and for other conditions: an epidemiological stud. Int J Epidemiol 1994; 23: $155-60$

[30] Bhopal FG, Khan JS, Iqbal M. Surgical audit of acute appendicitis. JCPSP 1999; 9: 223-26.

[31] Addiss DG, Shaffer N, Fowler BS, Tauxe RV.The epidemiology of appendicitis and appendectomy in the United States.Am J Epidemiol 1990; 132: 910-25.

[32] Berry Jr J, Malt RA. Appendicitis near its centenary. Ann Surg 1984; 200:567-75.

[33] . Mariadason JG, Wang WN, Wallack MK, Belmonte A, Matari H. Negative appendectomy rate as a quality metric in the management of appendicitis: impact of computed tomography, Alvarado score and the definition of negative appendicectomy. Ann. R. Coll. Surg. Engl. 2012; 94: 395- 401.

[34] Detmer DE, Nevers LE, Sikes ED Jr. Regional results of acute appendicitis care. JAMA 1981; 246: 1318-20.
[35] SCOAP Collaborative, Cuschieri J, Florence $\mathrm{M}$, et al. Negative appendectomy and imaging accuracy in the Washington State Surgical Care and Outcomes Assessment Program. Ann Surg 2008; 248:557.

[36] National Surgical Research Collaborative. Multicentre observational study of performance variation in provision and outcome of emergency appendicectomy. Br J Surg 2013; 100:1240.

[37] Güller U, Rosella L, McCall J, et al. Negative appendicectomy and perforation rates in patients undergoing laparoscopic surgery for suspected appendicitis. Br J Surg 2011; 98:589.

[38] Bakker OJ, Go PM, Puylaert JB, Kazemier G, Heij HA, Werkgroep richtlijn Diagnostiek en behandeling van acute appendicitis (2010) Guideline on diagnosis and treatment of acute appendicitis: imaging prior to appendectomy is recommended.Ned Tijdschr Geneeskd 54:A303

[39] Korndorffer JR Jr, Fellinger E, Reed W (2010) SAGES guideline for laparoscopic appendectomy. Surg Endosc 24:757-761

[40] Chiarugi M, Buccianti P, Decanini L, Balestri R, Lorenzetti L, Franceschi M, Cavina E (2001) "What you see is not what you get" a plea to remove a "normal" appendixduring diagnostic laparoscopy. Acta chir belg 101: 243-245

[41] Baigrh RJ, Dehn CB, Fowler SM, Dunn DC. Analysis of 8651 appendicectomies in England and Wales during 1992. Br J Surg 1995; 82: 933.

Citation: Chandio A et.al, "Can the Negative Appendicectomy Rate be Minimized?”, International Journal of Research Studies in Medical and Health Sciences. 2020; 5(3): 20-26.

Copyright: (C) 2020 Chandio A et.al, This is an open-access article distributed under the terms of the Creative Commons Attribution License, which permits unrestricted use, distribution, and reproduction in any medium, provided the original author and source are credited. 